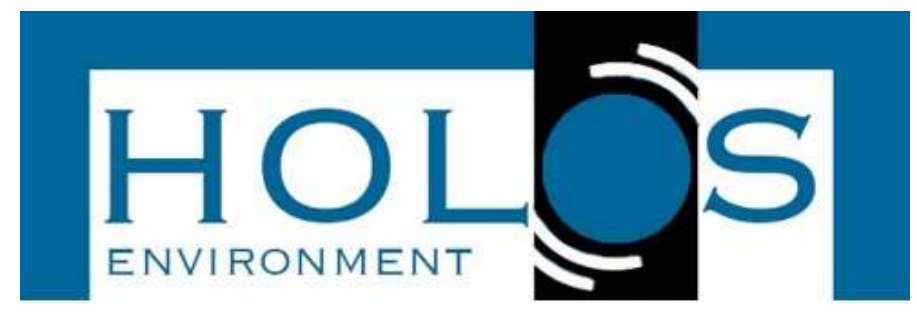

\title{
A QUALIDADE DE VIDA EM UNIDADES RURAIS PLANEJADAS PELA PERMACULTURA AVALIADA COM BASE NO MESMIS
}

\section{QUALITY OF LIFE IN PERMACULTURE FARMS EVALUATED USING MESMIS}

\author{
Leila Lessandra Paiter ${ }^{1}$; Leticia dos Santos ${ }^{1}$; Marcelo Venturi ${ }^{1}$; Arthur Schmidt Nanni ${ }^{1}$
}

Artigo recebido em: 15/03/2018 e aceito para publicação em: 27/08/2018.

DOI: http://dx.doi.org/10.14295/holos.v18i2.12268

\begin{abstract}
Resumo: Este artigo apresenta um estudo de caso realizado pelo Projeto Terra Permanente, que teve como objetivo avaliar se houve melhoria na qualidade de vida de agricultores/as da grande Florianópolis a partir da adoção dos princípios da permacultura como forma de manejo em suas unidades familiares de produção (UFP). Para avaliar a qualidade de vida antes, durante e após o curso de planejamento em permacultura (PDC, do inglês Permaculture Design Course), foram acompanhadas quatro UFP ao longo de dois anos. Foi utilizada como referência metodológica o "Marco para a Avaliação de Sistemas de Manejo Incorporando Indicadores de Sustentabilidade" - MESMIS - com adaptações necessárias às éticas e princípios da permacultura gerando uma metodologia personalizada aqui proposta como "MESMIS permacultural". Os resultados obtidos indicam que além de melhorias na qualidade de vida dos integrantes das UFP, a metodologia "MESMIS permacultural" apresenta potencial para ser aplicada em outras pesquisas cujo enfoque precise abordar os princípios da permacultura.
\end{abstract}

Palavras-chave: Permacultura. Qualidade de vida. MESMIS. Sustentabilidade.

Abstract: This article presents a case study developed by Terra Permanente project and its objective was to evaluate if there was life quality advances for four farmers' family in Santa Catarina State (Southern Brazil) after the permaculture principles adoption on their farm management. To evaluate the life quality before, along and after the Permaculture Design Course (PDC) conclusion, it was monitored four familiar farms during two years. It was used "Evaluating the sustainability of complex socio-environmental systems." - MESMIS framework - as reference, with some customizations needed to approximate to permaculture ethics and design principles. Some results obtained reveals the life quality advances clearly. Thus, the customized MESMIS methodology here applied it was dubbed as Permaculture MESMIS. It shows potential to be applied to surveys that address permaculture farms sustainability.

Keywords: Permaculture. Quality of life. MESMIS. Sustainability.

\section{INTRODUÇÃO}

Este estudo é resultado das ações desenvolvidas no projeto Terra permanente -

\footnotetext{
${ }^{1}$ Núcleo de Estudos em Permacultura da Universidade Federal de Santa Catarina. (UFSC), Florianopolis, SC. E-mails: (leilapaiter2012@gmail.com,legeografia@gmail.com,marcelo.venturi@ufsc.br, neperma.ufsc@gmail.com.
} 
produzindo alimentos orgânicos com a mata atlântica, uma iniciativa do Núcleo de Estudos em Permacultura (NEPerma) da Universidade Federal de Santa Catarina (UFSC). O projeto teve como componente de extensão, a realização de um Curso de Planejamento Permacultural ou do inglês, "Permaculture Design Course" (PDC), voltado para agricultores e extensionistas rurais atuantes na região da grande Florianópolis. A proposta da realização desse curso foi estimular a transição da produção convencional de alimentos para uma condição orgânica, através de uma visão sistêmica de processos e técnicas que operam em harmonia com a natureza. Todavia, o objetivo principal não foi apenas a produção de alimentos, mas também, auxiliar na promoção da melhoria da qualidade de vida dos envolvidos através adoção da permacultura e da bagagem técnica que esta faz uso.

Inspirado na permacultura, o projeto Terra permanente parte do pressuposto que a qualidade de vida é a condição em que as pessoas se encontram referente a sua autossuficiência (MOLLISON, B., 1999). Isso inclui fatores econômicos, que visam a produção e comercialização de alimentos; sociais, que buscam empoderamento das comunidades e; ambientais, que se referem à manutenção dos ecossistemas em que as famílias estão inseridas, compreendendo, assim, uma cultura de permanência local. A pergunta-chave "A permacultura pode melhorar a qualidade de vida dos agricultores?" exigiu a formulação de uma metodologia qualiquantitativa, capaz de responder ou não esta questão. Para isso foi utilizada como referência metodológica o "Evaluating the sustainability of complex socio-environmental systems." - MESMIS framework - (LÓPEZRIDAURA; MASERA; ASTIER, 2002), com adaptações necessárias aos princípios da permacultura.

A estrutura deste artigo apresenta um referencial teórico das éticas e princípios da permacultura e a sua relação com a qualidade de vida e bem-estar das pessoas. Seguido disso, referencia o MESMIS e apresenta a metodologia "MESMIS permacultural". Logo após, mostra os resultados de um estudo de caso onde o "MESMIS permacultural" foi aplicado e tece conclusões finais.

\subsection{A permacultura}

Em meados da década de 1970 muitas pessoas ao redor do mundo perceberam que estavam vivendo em meio a uma crise ambiental, por conta do crescimento da sociedade industrial de consumo (HOLMGREN, D, 2013). Assim, elas começaram a pensar e se 
organizar a respeito do que poderiam fazer para reverter tal situação. Nesse contexto, Bill Mollison e David Holmgren sistematizaram princípios e técnicas para uma "agricultura permanente", inspirada em padrões naturais, que não necessitasse de produtos tóxicos, nem de exploração de mão-de-obra (MOLLISON; HOLMGREN, 1987). Com isso surgiu a permacultura, que com o passar dos anos teve seu conceito ampliado para "cultura permanente" (MOLLISON, B, 1998), considerando que não só a agricultura, mas que a cultura, na sua totalidade, deveria ser pensada para a reversão desse quadro de crise ambiental.

Assim, a permacultura além de uma ciência holística de cunho socioambiental, passa a ser uma filosofia de vida onde o pensar e viver consideram que os seres humanos são parte integrante da natureza e não dominadores dela. Nesse contexto, o ser humano entra como ator que promove os processos de interações naturais favorecendo e potencializando-os com viés na produção de alimentos, energia, água e outros itens necessários à vida humana (SANTOS, L, 2014).

Adotada em muitas partes do mundo como instrumento de planejamento de unidades rurais, a permacultura busca melhorar a eficiência na gestão das mesmas, buscando otimizar o uso dos recursos naturais, bem como o gasto de energia por parte das pessoas. Na prática, com o tempo a permacultura passa a ser incorporada nas vidas daqueles que a adotam, modificando suas aspirações e modos de enxergar o que realmente é qualidade de vida e, que esta pode ser alcançada junto à natureza. No avanço do bem-estar geralmente instala-se um cenário onde a autossuficiência estimula a permanência das pessoas no campo e, em inúmeros casos, também a migração humana dos meios urbanos para o ambiente rural.

A partir de experiências práticas, o conceito de permacultura continuou se desenvolvendo nessas quatro últimas décadas e atualmente ela é fundamentada em três éticas, sendo a principal base para todo trabalho a ser realizado. As éticas da permacultura envolvem três grandes necessidades a respeito de nossa convivência com o planeta Terra, que basicamente expressam sua preocupação com os quesitos ambientais, sociais e econômicos (HOLMGREN, D, 2013). Assim, estas três éticas constituem-se nos vértices do triângulo da sustentabilidade, onde a sua bissetriz é o ponto de equilíbrio a ser alcançado. Num segundo âmbito, são colocados doze princípios de planejamento, que auxiliam no direcionamento das ações. A Figura 1 apresenta uma sistematização de todos os princípios. 
Figura 1 - Éticas (centrais) e princípios de planejamento (periféricos) da permacultura propostos por Holmgren (2013), Dixon e Spotten (2014), Harland (2018) e WithOnePlanet (2017)

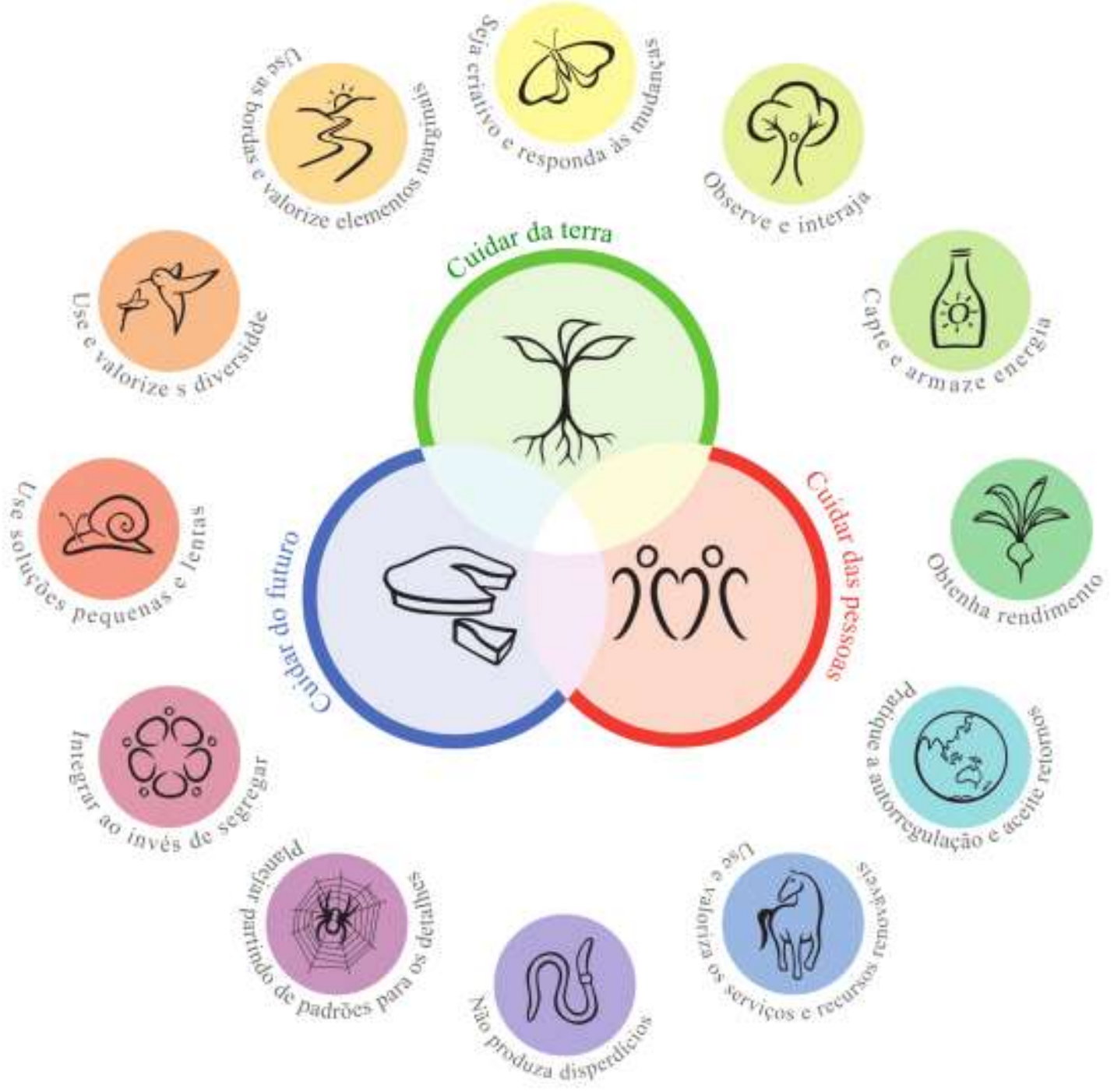

Fonte: Modificado e traduzido de http://holmgren.com.au/essence-of-permaculture-free/. Acesso em 02 de set/2018.

A primeira ética "Cuidar da terra" considera o quesito ambiental e nos remete a obrigação de cuidar do planeta com a consciência de que à Terra é a casa de todos, nos auxiliando a compreender que tudo e todos estão interligados e somos interdependentes (HOLMGREN, D, 2013). Já a segunda, "Cuidar das pessoas" define uma linha de ação para questões sociais e busca alertar para as necessidades de cada um: saúde física e mental, qualidade de vida, autonomia política, moradia, segurança alimentar, direitos humanos, educação (HOLMGREN, D, 2013). A terceira, "Cuidar do futuro" (DIXON; SPOTTEN, 2014; HARLAND, M, 2018; WITHONEPLANET, 2017), parte do pressuposto da abundância, onde 
se cada um compartilhar o excedente que tem e as responsabilidades pelo que não tem, assim não faltará nada a ninguém. Além disso, trabalha questões de gestão da casa, que passa pelo reconhecimento de limites de crescimento, incluindo o populacional, prevendo sua estabilização para estar em consonância com a capacidade de suporte do planeta.

No guarda-chuvas das éticas estão doze princípios de planejamento do espaço/território que trabalham a interação entre a espécie humana e a natureza, passando pela gestão de recursos naturais como energia e água, a utilização de processos naturais evolutivos como inspiração para estabelecer no espaço e no tempo um ambiente que possa abrigar o ser humano, dentro de suas necessidades básicas, buscando desta forma, uma harmonia de convivência entre pessoas e o meio que as abrigam.

\subsection{Permacultura e qualidade de vida}

A qualidade de vida pode ser entendida de diferentes formas e em muitos casos ela é sinônimo de bem-estar. Dependendo do ponto de vista usado para avaliar a qualidade de vida, a mesma pode ser mensurada de diferentes formas. Vinculada a economia (senso comum), a qualidade de vida pode ser medida por meio do Produto Interno Bruto (PIB), que considera que quanto maior for o PIB de um país, melhor será a qualidade de vida per capita de sua população. Este método é bastante reducionista, pois, desconsidera os fatores social e ambiental na avaliação. Está calcado, portanto, na falsa impressão de que a qualidade de vida está atrelada apenas a capacidade de consumo das pessoas.

Assim, a avaliação da qualidade de vida deve considerar também os aspectos pessoal, social e ambiental. Segundo (MOLLISON, B., 1999), a permacultura promove a diversidade, a resiliência e a estabilidade dos ecossistemas naturais, para que possam prover energia, moradia e alimentação humana de forma harmoniosa com o ambiente. Com isso, "a permacultura e bem-estar podem ser usados como estrutura conceitual para estimular pessoas em um nível pessoal e conectá-las com mudanças positivas na sociedade e no mundo natural" (NETWORK OF WELLBEING, 2017).

Segundo Ross Mars e Jenny Mars (2007) a permacultura oferece qualidade de vida às pessoas através de ambientes restaurados que podem atender as suas necessidades. Para muitos, a permacultura é uma filosofia de vida onde a liberdade de tomar decisões e 
ser responsável pela própria vida, pode promover um bem-estar próprio, para outros e para o planeta.

De acordo com Lockyer e Veteto (2013), a "permacultura é uma poderosa via para entender como a natureza funciona [...], incluindo o cultivo de plantas, condições climáticas, fontes de energia, etc, considerando esses elementos como parte de um estilo de vida sustentável".

Dentro desse contexto, compreende-se que por aproximar as pessoas dos ambientes naturais, a permacultura funciona como uma importante "ferramenta" de promoção do bem-estar, pois, fornece condições para uma melhor qualidade de vida. Entende-se então, que na medida em que as pessoas incorporam as éticas e os princípios da permacultura, mais inseridas nos ecossistemas estarão e, portanto, serão possuidoras de um melhor bem-estar e qualidade de vida.

\section{METODOLOGIA}

O processo de avaliação da pergunta proposta envolveu o acompanhamento ao longo de dois anos, das mudanças em quatro unidades familiares produtivas (UFP) situadas na grande Florianópolis. Elas foram escolhidas devido aos seus gestores adotarem a permacultura como instrumento de planejamento, manejo e tomada de decisões.

De acordo com López-Ridaura; Masera; Astier (2002), o "Marco para a Avaliação de Sistemas de Manejo Incorporando Indicadores de Sustentabilidade" - MESMIS, é um método de pesquisa que permite avaliar e monitorar a sustentabilidade de sistemas de manejo e recursos naturais. Ele busca fornecer uma visão interdisciplinar e abrangente para compreender as fragilidades e as potencialidades de um sistema de manejo e gestão, considerando os processos ambientais, cruzando com as esferas sociais e econômicas. $\mathrm{O}$ objetivo é analisar o quão sustentável é o agroecossistema e quais são os pontos críticos que interferem ou favorecem a sua sustentabilidade. Uma das principais características atribuídas à metodologia é seu caráter participativo, em que se promove a discussão e o retorno entre os avaliadores e avaliados.

O ciclo de avaliação proposto pelo MESMIS consiste inicialmente na determinação dos sistemas de manejo a serem avaliados, seguido do reconhecimento dos pontos críticos que impedem a sustentabilidade, da seleção dos indicadores a serem adotados, da medição e monitoramento dos desses indicadores, da obtenção de resultados - os quais 
indicam os principais obstáculos e pontos que favorecem a sustentabilidade - e, por fim, há a elaboração das conclusões e recomendações.

A escolha do MESMIS como base metodológica justifica-se pelos aspectos convergentes com a proposta de avaliação da qualidade de vida. Ela requer uma equipe interdisciplinar que envolve avaliadores, tais como, especialistas em distintas áreas, atores sociais locais, lideranças comunitárias, técnicos e principalmente agricultores. Por esta razão, trata-se de uma metodologia participativa que permite a comparação e evolução do sistema ao longo do tempo.

Até o presente, não existem registros de adaptações da metologia MESMIS voltadas a atender a permacultura. Existem apenas avaliações utilizando o MESMIS na comparação entre UFP permaculturais com outras formas de planejamento e manejos de UFP. Uma destas comparações foi apresentada por Certomà e Migliorini (2011), mostrando que entre unidades estudadas, as permaculturais possuíam menor dependência de financiamentos externos e maior eficácia produtiva, mas nas questões sociais e ambientais se encontravam equilibradas com as demais unidades produtivas manejadas com base em outras óticas.

A aplicação do MESMIS sem adaptações para casos específicos, como o de unidades permaculturais, se mostra limitada ao focar principalmente questões que levam a uma visão produtivista. No caso da permacultura pode-se enfatizar a autonomia e a qualidade de vida, tendo a produtividade com fins econômicos como complementar. Estas características justificam a necessidade de uma metodologia adaptada às éticas e princípios da permacultura e, que ainda possa ser modificada de acordo com cada nova realidade de maneira mais sistêmica. Assim, a aplicação do MESMIS para espaços rurais planejados segundo a lógica da permacultura exigiu a construção de uma metodologia específica que considera as particularidades dessa. Dessa forma, a criação do método "MESMIS permacultural", metodologia aqui proposta, foi estruturada em seis passos.

O primeiro passo envolveu a seleção das UFP a serem avaliadas antes da realização do Curso de Planejamento em Permacultura (PDC), um momento logo após a conclusão do PDC e outro, após um ano decorrido dessa. As UFP selecionadas foram indicadas por extensionistas rurais que atuam na Empresa de Pesquisa Agropecuária e Extensão Rural de Santa Catarina (EPAGRI). A seleção considerou a predisposição e simpatia das famílias para com processos de produção de alimentos dentro da lógica orgânica e/ou 
agroecológica, bem como a disponibilidade e interesse em participar do processo de pesquisa-ação proposto pelo projeto Terra Permanente.

O segundo passo compreendeu a realização do PDC para empoderar os gestores das UFP ora selecionadas, para estabelecer um canal de diálogo compreensível do ponto de vista da permacultura. Nesse curso, às quatro UFP foram alvos dos projetos finais de planejamento permacultural, uma etapa obrigatória. Assim, os gestores não partiram do zero para o entendimento de como se daria a implantação do planejamento permacultural em suas UFP após o PDC.

O terceiro passo buscou relacionar as variáveis propostas pelo MESMIS com as éticas e princípios de planejamento da permacultura. Esta etapa mostrou-se mais simples, pois, ambos tratam de forma muito similar a sustentabilidade, sendo "Cuidar da terra" (ambiental), "Cuidar das pessoas" (social) e "Cuidar do futuro" (econômica).

O quarto passo considerou o contexto das UFP e a pergunta em pauta, onde se percebeu que, para uma avaliação mais coerente seria preciso pensar em atributos relevantes com a finalidade da perspectiva permacultural. Por isso, ao invés de utilizar os sete atributos gerais propostos pelo MESMIS - 1) produtividade; 2) patrimônio; 3) estabilidade; 4) resiliência; 5) confiabilidade; 6) adaptabilidade e 7) autossuficiência - foi realizada uma adaptação que considera os doze princípios de planejamento da permacultura, que incluem às três éticas e vice-versa, caracterizando os pilares básicos para a qualidade de vida e bem-estar.

No quinto passo, foram elencados pontos críticos para a sustentabilidade das UFP. Segundo López-Ridaura; Masera; Astier (2002), os pontos críticos são os aspectos ou processos que limitam ou melhoram a capacidade dos agroecossistemas de serem sustentados ao longo do tempo. Para isso, os mesmos foram mapeados no decorrer das etapas do PDC e também enfatizados em um Diagnóstico Rural Participativo - DRP (VERDEJO, M. E., 2010) - que foi desenvolvido junto com os agricultores, técnicos e avaliadores, através de uma oficina onde os participantes puderam compartilhar as suas experiências, dúvidas e também identificar fragilidades e potencialidades das UFP.

O sexto passo envolveu a construção de um questionário de avaliação da qualidade de vida. Desta forma, para cada um dos doze princípios de planejamento da permacultura foram formuladas três perguntas com base nas éticas da permacultura, resultando um total de 36 questões. Onde possível, tentou-se utilizar a escala de Likert (LIKERT, 1932) para 
padronizar as opções de resposta, porém, por se tratar de um estudo de caso, foram priorizadas respostas específicas, ou seja, mais próximas da realidade das UFP avaliadas. Para facilitar a compreensão das perguntas para os entrevistados, foram adotadas expressões faciais para cada resposta, que receberam pontuações com valores entre um (1) e cinco (5), onde "1" é ruim e " 5 " é bom para a qualidade de vida. (Tabela 1).

Tabela 1 - Questionário de entrevista para avaliação da qualidade de vida nas UFP Cuidar da terra (ambiental)

\begin{tabular}{|c|c|c|c|c|c|}
\hline \multicolumn{6}{|c|}{ o de Pontuação } \\
\hline & & & & & \\
\hline \multirow{2}{*}{$\begin{array}{l}1 \text { - Observe e } \\
\text { interaja }\end{array}$} & \multicolumn{5}{|c|}{$\begin{array}{l}\text { O quanto você consegue ver e manejar a sua propriedade de maneira } \\
\text { integrada com a natureza? }\end{array}$} \\
\hline & Nada & Pouco & Medianamente & Bem & Integralmente \\
\hline \multirow{2}{*}{$\begin{array}{c}2 \text { - Capte e } \\
\text { armazene energia }\end{array}$} & \multicolumn{5}{|c|}{ Quanto de energia (todas as energias) você tem na sua propriedade? } \\
\hline & Nada & Pouco & Bastante & Muita & Sobra \\
\hline \multirow{2}{*}{$\begin{array}{l}3 \text { - Obtenha } \\
\text { rendimento }\end{array}$} & \multicolumn{5}{|c|}{ Quanto você consegue produzir alimentos para alimentar a sua família? } \\
\hline & Nada & Pouco & Metade & Quase & \\
\hline \multirow{2}{*}{$\begin{array}{c}4 \text { - Pratique } \\
\text { autorregulação e } \\
\text { aceite retornos }\end{array}$} & \multicolumn{5}{|c|}{$\begin{array}{l}\text { Ao produzir alimentos de ciclo curto (meses), você costuma preparar à terra } \\
\text { com revolvimento? }\end{array}$} \\
\hline & \multicolumn{3}{|l|}{ Sempre } & Raramente & Nunca \\
\hline \multirow{2}{*}{$\begin{array}{c}5 \text { - Use e valorize } \\
\text { recursos } \\
\text { renováveis }\end{array}$} & \multicolumn{5}{|c|}{ Você conserva os serviços e recursos da natureza? } \\
\hline & Nunca & Às ve & $\begin{array}{l}\text { Na med } \\
\text { poss }\end{array}$ & Quase sen & Sem \\
\hline \multirow{2}{*}{$\begin{array}{l}6 \text { - Não produza } \\
\text { desperdícios }\end{array}$} & \multicolumn{5}{|c|}{ os na propriedade? } \\
\hline & Nada & Pou & $\begin{array}{l}\text { Na medida do } \\
\text { possível }\end{array}$ & Mu & Tudo \\
\hline \multirow{2}{*}{$\begin{array}{l}7 \text { - Planejamento } \\
\text { partindo dos } \\
\text { padrões para os } \\
\text { detalhes }\end{array}$} & \multicolumn{5}{|c|}{$\begin{array}{l}\text { Você avalia onde o planejamento deve ser implantado/desenvolvido na } \\
\text { propriedade? }\end{array}$} \\
\hline & Não & Pol & Às v€ & Quase & Sem \\
\hline \multirow{2}{*}{$\begin{array}{l}8 \text { - Integrar ao } \\
\text { invés de segregar }\end{array}$} & \multicolumn{5}{|c|}{ Você consegue ver e fazer a integração entre elementos na paisagem? } \\
\hline & Nunca & Raramente & Ocasionalme & Frequen & Sem \\
\hline \multirow{2}{*}{$\begin{array}{l}9 \text { - Use soluções } \\
\text { pequenas e lentas }\end{array}$} & \multicolumn{5}{|c|}{ Ao iniciar uma atividade você pensa em obter resultados... } \\
\hline & Imediatamente & Rápidos & A curto prazo & A médic & A lor \\
\hline \multicolumn{6}{|c|}{10 - Use e valorize Quantas espécies/culturas você cria/desenvolve na propriedade? } \\
\hline & Uma & Três & Seis & Doze & $>24$ \\
\hline \multirow{2}{*}{$\begin{array}{c}11 \text { - Use as bordas } \\
\text { e valorize os } \\
\text { elementos } \\
\text { marginais }\end{array}$} & \multicolumn{5}{|c|}{$\begin{array}{l}\text { Você protege/usa margens de rios, açudes, limites da propriedade com } \\
\text { vegetação silvestre? }\end{array}$} \\
\hline & Nunca & Raramente & Ocasionalmente & Frequent & Sempre \\
\hline \multicolumn{6}{|c|}{$\begin{array}{l}12 \text { - Seja criativo e Quando você tem um problema ambiental, você procura compreendê-lo antes } \\
\text { responda às }\end{array}$} \\
\hline & Nunca & Raramente & Ocasionalmente & Frequentemente & Sempre \\
\hline
\end{tabular}


Tabela 1 - Questionário de entrevista para avaliação da qualidade de vida nas UFP (continuação) Cuidar das pessoas (social)

\begin{tabular}{|c|c|c|c|c|c|}
\hline $\begin{array}{l}\text { io de } \\
\text { amento }\end{array}$ & Pontuaçã 1 & & & & \\
\hline \multirow{2}{*}{$\begin{array}{l}13 \text { - Observe e } \\
\text { interaja }\end{array}$} & \multicolumn{5}{|c|}{ Você se relaciona com vizinhos? } \\
\hline & Nunca & Raramente & Ocasionalmente & Frequentemente & Se \\
\hline \multirow{2}{*}{$\begin{array}{l}14 \text { - Capte e } \\
\text { armazene energia }\end{array}$} & \multicolumn{5}{|c|}{ Você busca como fonte de energia, produtos e serviços de vizinhos? } \\
\hline & Nunca & Raramente & Ocasionalmente & Frequentemente & Sem \\
\hline \multirow{2}{*}{$\begin{array}{l}15 \text { - Obtenha } \\
\text { rendimento }\end{array}$} & \multicolumn{5}{|c|}{$\begin{array}{l}\text { Os alimentos que são produzidos na propriedade são verdadeirament } \\
\text { saudáveis? }\end{array}$} \\
\hline & Nada sau & Pou & Mediana & Bast & $\begin{array}{l}\text { Mu } \\
\text { saud }\end{array}$ \\
\hline \multirow{2}{*}{$\begin{array}{c}16 \text { - Pratique } \\
\text { autorregulação e } \\
\text { aceite retornos }\end{array}$} & \multicolumn{5}{|c|}{ Você costuma produzir alimentos priorizando a alimentação da sua família? } \\
\hline & Nunca & Raramente & Ocasionalmente & Frequentemente & Sen \\
\hline \multirow{2}{*}{$\begin{array}{c}17 \text { - Use e valorize } \\
\text { recursos } \\
\text { renováveis }\end{array}$} & \multicolumn{5}{|c|}{$\begin{array}{l}\text { Ao utilizar animais, água, solos e outros recursos naturais, } \\
\text { devolvê-los à natureza da mesma forma que os encontrou? }\end{array}$} \\
\hline & Nunca & Raramente & Ocasionalmente & Frequentemente & Ser \\
\hline \multirow{2}{*}{$\begin{array}{l}18 \text { - Não produza } \\
\text { desperdícios }\end{array}$} & \multicolumn{5}{|c|}{ Você reutiliza as sobras (“lixos") da propriedade? } \\
\hline & Nunca & Raramente & Ocasionalmente & nemente & Sempre \\
\hline
\end{tabular}

19 - Planejamento Ao enxergar sua comunidade, você vê pessoas que são importantes para sua partindo dos padrões para os detalhes

20 - Integrar ao invés de segregar felicidade?

\begin{tabular}{l|l|l|l|l} 
Nunca & Raramente & Ocasionalmente Frequentemente & Sempre
\end{tabular}

Você costuma abrir sua propriedade para vizinhos, amigos, busca fazer mutirões, participa de ações coletivas na comunidade?

\begin{tabular}{l|l|l|l|} 
Nunca & Raramente & Ocasionalmente|Frequentemente & Sempre
\end{tabular}

Ao se deparar com um problema de relacionamento social, o que você faz?

21 - Use soluções pequenas e lentas

\begin{tabular}{c|c|c|c|c}
$\begin{array}{c}\text { Resolvo } \\
\text { mediatamente } \\
\text { do jeito que der }\end{array}$ & $\begin{array}{c}\text { Tento resolver } \\
\text { em curto prazo }\end{array}$ & $\begin{array}{c}\text { Tento resolver } \\
\text { em médio prazo }\end{array}$ & $\begin{array}{c}\text { Tento resolver a } \\
\text { longo prazo }\end{array}$ & $\begin{array}{c}\text { Espero que a } \\
\text { conscientização } \\
\text { mútua resolva }\end{array}$ \\
\hline
\end{tabular}

Você costuma respeitar as opções das demais pessoas: etnia, opção sexual,

22 - Use e valorize gênero, idades, religião, cultura e busca se relacionar com todas da mesma a diversidade maneira?

\begin{tabular}{l|l|l|l|l} 
Nunca & Raramente & Às vezes & Frequentemente & Sempre
\end{tabular}

23 - Use as bordas Você costuma valorizar locais como margens de rio, açudes, o entorno da e valorize os casa, divisa com os vizinhos, entendendo que estes locais são bons para elementos confraternizar com outras pessoas?

\begin{tabular}{l|c|c|c|c|c|} 
marginais & Nunca & Raramente & Às vezes & Frequentemente & Sempre
\end{tabular}

Você acredita que ao produzir alimentos saudáveis você pode criar uma

24 - Seja criativo e sociedade melhor? responda às mudanças

Não acredito

\begin{tabular}{c|c}
$\begin{array}{c}\text { Já acreditei no } \\
\text { passado }\end{array}$ & Talvez
\end{tabular}

Sim, acredito

Sim, e estimulo as pessoas a produzirem 
Tabela 1 - Questionário de entrevista para avaliação da qualidade de vida nas UFP (conclusão)

Cuidar do futuro (econômico)

\begin{tabular}{|c|c|c|c|c|c|}
\hline \\
\hline planejamento & (2) 1 & ○) 2 & $\because 3$ & (ت) 4 & (2) 5 \\
\hline \multirow{2}{*}{$\begin{array}{c}25 \text { - Observe e } \\
\text { interaja }\end{array}$} & \multicolumn{5}{|c|}{$\begin{array}{l}\text { Você observa a natureza enquanto produz e busca facilitar as coisas para ela } \\
\text { e para você? }\end{array}$} \\
\hline & Nunca & Raramente & Ocasionalmente & Frequentemente & Sempre \\
\hline \multirow{2}{*}{$\begin{array}{l}26 \text { - Capte e } \\
\text { armazene energia }\end{array}$} & \multicolumn{5}{|c|}{ Quanto de insumo vem de fora da propriedade? } \\
\hline & Nada & Pouca coisa & Alguma coisa & Quase todo & Todo \\
\hline & \multicolumn{5}{|c|}{ Quanto você compartilha/comercializa da sua produção de alimentos? } \\
\hline $\begin{array}{l}27 \text { - Obtenha } \\
\text { rendimento }\end{array}$ & $\begin{array}{l}\text { Compartilho } \\
\text { somente para } \\
\text { gerar renda }\end{array}$ & $\begin{array}{l}\text { Só para pagar } \\
\text { as contas e ter } \\
\text { uma reserva }\end{array}$ & $\begin{array}{l}\text { Só para pagar } \\
\text { as contas }\end{array}$ & $\begin{array}{c}\text { Não compartilho } \\
\text { nada. }\end{array}$ & $\begin{array}{l}\text { Compartilho só } \\
\text { o excedente. }\end{array}$ \\
\hline
\end{tabular}

28 - Pratique Busca auxílio e escuta sugestões quando tem problemas na produtividade? autorregulação e aceite retornos

Nunca

Raramente OcasionalmenteFrequentemente Sempre

29 - Use e valorize Você costuma usar recursos naturais renováveis? recursos renováveis

30 - Não produza desperdícios

Nunca

Raramente Ocasionalmente Frequentemente

Sempre

Você costuma introduzir o rejeito (sobras) de alguma atividade em outras atividades de geração de renda para a propriedade?

Nunca $\mid$ Raramente Ocasionalmente|Frequentemente| Sempre

31 - Planejamento Sua forma de cultivo procura imitar a natureza, como plantio de árvores em partindo dos

padrões para os detalhes

32 - Integrar ao invés de segregar

33 - Use soluções
pequenas e lentas

grupo (SAF), consórcios de muitas plantas no mesmo espaço?

Nunca $\quad$ Raramente OcasionalmenteFrequentemente Sempre

Você busca associar sua produção com a de outros produtores?

\begin{tabular}{c|c|c|c|} 
Nunca & Raramente & OcasionalmenteFrequentemente & Sempre
\end{tabular}

Ao se deparar com um problema de produção você busca:

\begin{tabular}{l|l|l|l|l} 
"Zerar" a área & Resolver no & Resolver no & Resolver no & Entender o
\end{tabular} do problema curto prazo médio prazo longo prazo com problema e resolver com

químicos

químicos.

orgânico

agroecológico

manejo ecológico

O quão diversificados são seus cultivos? (incluindo animais)

\begin{tabular}{|c|c|c|c|c|c|}
\hline $\begin{array}{l}34 \text { - Use e valorize } \\
\text { a diversidade }\end{array}$ & Não diversifico & $\begin{array}{l}\text { Uso poucas } \\
\text { espécies } \\
\text { (até 3) }\end{array}$ & $\begin{array}{l}\text { Mantenho de } 4 \\
\text { a } 9 \text { espécies }\end{array}$ & $\begin{array}{l}\text { Mantenho de } 10 \\
\text { a } 24 \text { espécies }\end{array}$ & $\begin{array}{l}\text { Cultivo de tudo } \\
\text { um pouco e } \\
\text { tudo conjugado }\end{array}$ \\
\hline
\end{tabular}

35 - Use as bordas Você usa margens (açude, cercas, rios, entorno da casa) para produzir e valorize os alimentos para consumo e/ou comercialização? elementos marginais

Nunca

Raramente Ocasionalmente Frequentemente

Sempre

Ao se deparar com um problema de escoamento da produção você:

36 - Seja criativo e responda às mudanças

Reclama

Não faz nada

Espero o poder
público
solucionar

Busco soluções individuais de escoamento

\subsection{Estudo de caso}

No intuito de aplicar o MESMIS permacultural, um total de três entrevistas foram realizadas com cada um dos gestores das quatro UFP, sendo uma antes do PDC, outra 
logo após a conclusão do PDC e uma última após o decorrer de um ano da conclusão do curso.

A UFP1 está localizada no município de São Bonifácio e é gerenciada por uma família de agricultores constituída por quatro membros, sendo eles, o pai e três filhos. Em 2007 foi iniciada a produção de alimentos orgânicos e antes disso, a família trabalhava principalmente na produção de fumo. Cabe a um dos irmãos a tarefa de trocar conhecimentos com pessoas e entidades fora da UFP, sendo que apenas este participou do PDC com o projeto Terra Permanente e ficou responsável por dialogar com os familiares sobre os temas que a permacultura trata. Antes do PDC esta UFP já possuía práticas agroecológicas que são condizentes com os princípios da permacultura, como o não uso de agroquímicos no plantio, preservação das águas e da floresta nativa e o cultivo integrado de diferentes espécies. A comercialização da produção dá-se em feiras livres no próprio município e em outros vizinhos.

A UFP2 localiza-se no município de Rio Fortuna e é gerenciada por uma família de quatro pessoas, sendo que o filho e a filha - jovens - realizaram o PDC. Os pais já haviam trabalhado com plantação de fumo e nos últimos anos tentaram implantar propostas de turismo rural. Eles também são ligados ao movimento sindical da agricultura familiar e trabalham atualmente em uma cooperativa de pequenos agricultores da região.

A UFP3 situa-se no município de Águas Mornas e inicialmente era manejada por duas pessoas com perfil neorural (GIULIANI, G. M., 1990). Sua produção é voltada para o cultivo de morangos orgânicos em estufas com bancadas e aves de postura em sistema semi-intensivo. A comercialização se dá através de encomendas e um ponto de venda em Florianópolis. No final do acompanhamento pelo projeto a UFP passou a ser gerenciada por apenas uma pessoa.

A UFP4 localiza-se no município de São Pedro de Alcântara e foi adquirida no ano de 2006 com a proposta de ser uma ecovila para um grupo de sete famílias com perfil neorural. Todavia, apenas duas moradoras vivem definitivamente no local e iniciaram com cultivo de alimentos orgânicos em 2012 com a produção de hortaliças, frutas e ervas medicinais e alimentos processados conforme limitações sazonais. Elas têm intenção de produzir apenas para consumo próprio, trocas e doações. O principal objetivo da UFP é proporcionar qualidade de vida às pessoas que nela habitam e visitam. 
Os resultados das entrevistas foram compilados e inseridos em planilha eletrônica, utilizando o aplicativo LibreOffice para o cálculo da intensidade da qualidade de vida nos três momentos avaliados e a geração de gráficos do tipo AMOEBA (TEN BRINK; HOSPER; COLIJN, 1991). Este tipo de gráfico busca revelar, através de um padrão radial, a intensidade de ocorrência para uma condição multivariável. Assim, os resultados são apresentados a partir de linhas que partem do centro (pontuação "0") para a periferia (pontuação "5"), refletindo dessa forma a intensidade das respostas resultantes da aplicação do questionário de avaliação da qualidade de vida proposto pelo MESMIS permacultural.

Por fim, foi considerado que o grau de incorporação dos princípios de planejamento reflete o quão a permacultura pode contribuir com o bem-estar e a qualidade de vida, pois, mais próximo da natureza e de suas benesses, estará o permacultor.

\section{RESULTADOS E DISCUSSÃO}

A análise dos resultados utilizou os dados obtidos por meio da aplicação do questionário proposto pelo MESMIS Permacultural. Os dados foram inseridos em gráficos do tipo AMOEBA, que apresentam três polígonos, sendo um com a pontuação para a situação pré-PDC, outra que reflete a ocasião logo após a conclusão do curso e, uma última que mostra a condição, transcorrido um ano após a conclusão do PDC.

O monitoramento desses três momentos procurou avaliar se a participação no PDC e a incorporação das éticas e princípios da permacultura promoveram melhorias na qualidade de vida dos gestores rurais. Estes três momentos foram ainda divididos conforme as éticas da permacultura, sendo as perguntas de 1 a 12 para "Cuidar da Terra", 13 a 24 para "Cuidar das pessoas" e 25 a 36 para "Cuidar do futuro" (Figura 2). 
Figura 2 - Resultados das entrevistas para avaliação da qualidade de vida das famílias participantes da pesquisa
UFP1 UFP2
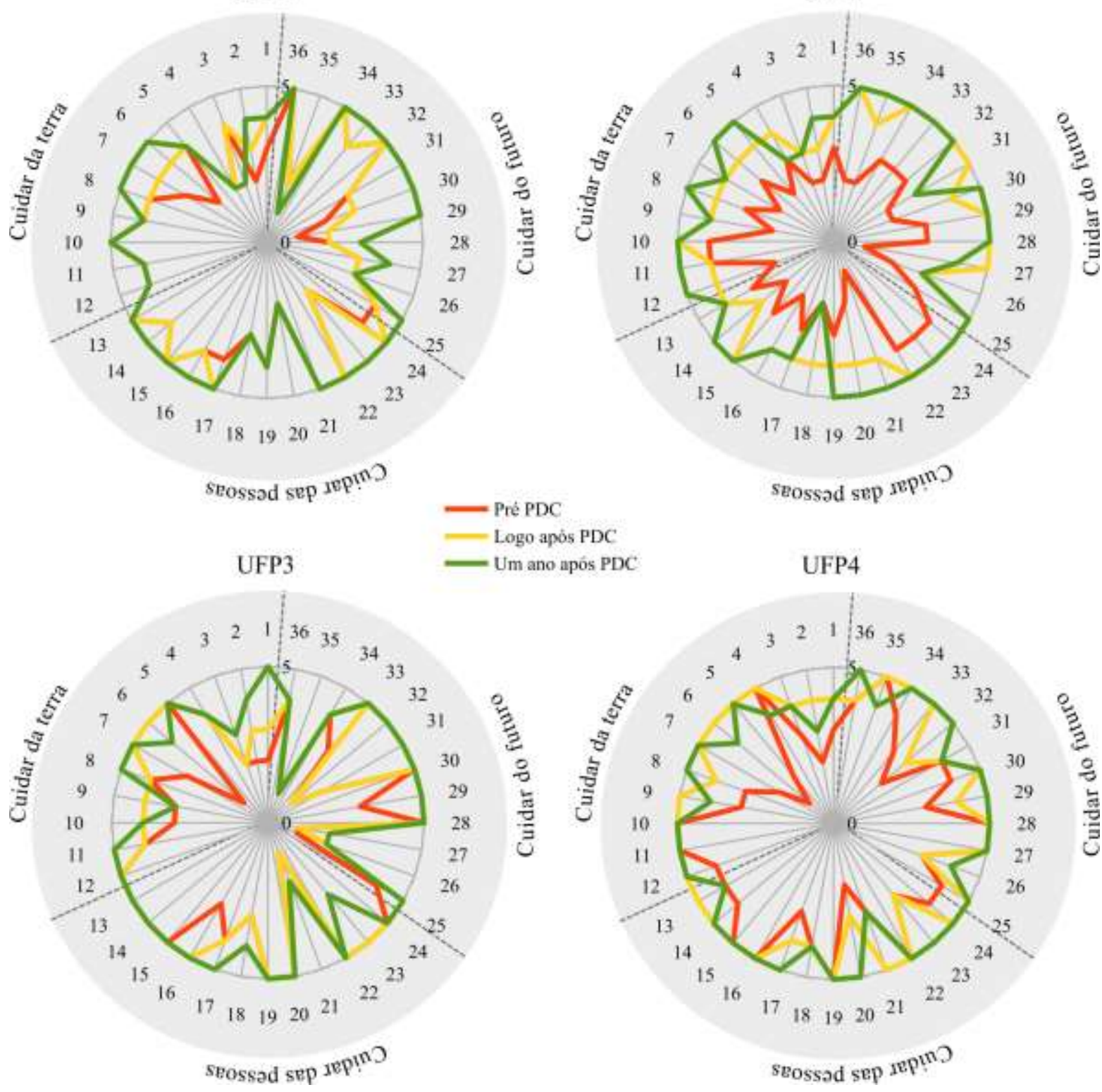

Fonte: Os autores

As respostas apontam que na UFP1, no que tange a ética de cunho ambiental "Cuidar da Terra", houveram melhorias significativas em cinco dos doze princípios de planejamento. Isso pode estar atrelado ao fato de nessa UFP já ter sido incorporado o cultivo orgânico desde 2007 e haver a prática do uso racional dos recursos naturais, portanto, no momento pré-PDC. Já para a ética "Cuidar das pessoas" houve uma tímida melhora, que em parte se reflete na intensa participação comunitária da família, principalmente com outros produtores de alimentos orgânicos que vendem seus produtos 
em parceria. Por último, para a ética "Cuidar do futuro" foram registradas melhorias em oito dos doze princípios de planejamento, refletindo aqui a influência da essência de cooperação ao invés de competição, proposta pela permacultura.

Acredita-se que a demora na adoção de práticas da permacultura na UFP1 esteja atrelada ao fato de que sua gestão é realizada por toda família, onde apenas uma pessoa teve a formação no PDC. Além disso, a tomada de decisões considera não apenas a autossuficiência, mas também a conjuntura financeira, pois, a renda se dá única e exclusivamente a partir das vendas dos produtos do local. Dessa forma, há o receio por parte dos demais integrantes da família em arriscar novos projetos.

Os resultados da UFP2 mostram melhorias expressivas principalmente entre a fase pré-PDC e logo após a sua conclusão. No que se refere a ética "Cuidar do futuro", houve avanço em todos os indicadores, refletindo bem a alternância entre o modelo de produção de alimentos convencional para o orgânico. Nas outras duas éticas, apenas um indicador de cada não obteve melhoria, evidenciando importância da incorporação dos princípios da permacultura na rotina da UFP. Os jovens que concluíram o PDC exerceram forte influência sobre seus pais, e incentivaram inúmeras mudanças no modo como a UFP é manejada. Apesar da jovem não estar mais envolvida diretamente no projeto, o jovem conseguiu tomar a frente da UFP com o apoio da mãe, que voltou a trabalhar na propriedade. Atualmente, a família produz alimentos agroecológicos, principalmente hortaliças e frutas. O escoamento da produção ocorre por meio da comercialização de cestas agroecológicas em municípios vizinhos, através de um sistema de agricultura apoiada pela comunidade (CSA, "Community Supported Agriculture").

Os resultados para a UFP3 demonstram que as éticas "Cuidar da Terra" e "Cuidar do futuro" tiveram avanço moderado, enquanto o princípio "Cuidar das Pessoas" obteve poucas mudanças para os diferentes momentos avaliados. Acredita-se que os princípios e práticas apresentados no PDC não foram incorporados de uma maneira tão rápida, devido ao fato dessa UFP ter contraído dívidas com infraestrutura para produção de morangos antes do PDC. Aliado a isso, um dos moradores, além de não ter incorporado a filosofia da permacultura, deixou de habitar a propriedade, o que resultou em apenas uma moradora manejando a mesma. Mesmo com esse cenário, destaca-se um ponto positivo que foi a maior preocupação de produção de subsistência por parte da agricultora que permaneceu, 
que passou a diversificar os cultivos usando a infraestrutura construída, ao invés de focar apenas na cultura do morango.

No caso da UFP4, verificou-se uma melhoria expressiva, sobretudo para a ética "Cuidar da Terra", mostrando a agregação de conhecimentos proporcionados pelo PDC. A ética "Cuidar do futuro" apresentou uma melhoria menos significativa, que pode estar atrelada ao fato das moradoras serem aposentadas e não dependerem da venda da produção para viver. Já a ética "Cuidar das pessoas" mostrou uma tímida melhoria, que pode estar vinculada ao descontentamento das duas moradoras fixas, em relação aos demais parceiros de ecovila que ainda não estão ativamente participando do processo. Assim, ambas buscam na sua relação de vizinhança, a construção do próprio bem-estar. Dessa forma, entende-se que o PDC contribuiu sobretudo nas questões condizentes com as práticas de manejo da terra, principalmente relacionas à produção de alimentos.

Com o intuito de compreender de forma sistêmica como se deram os avanços na melhoria da qualidade de vida das famílias participantes, foram somadas as pontuações de "1" a "5" para cada uma das trinta e seis perguntas. Assim, um escore total foi criado para revelar o conjunto das três éticas da permacultura, pois, uma não opera sem a interferência das demais. Os resultados foram inseridos em um gráfico de linhas para melhor evidenciar como se deu a evolução desses somatórios nos três momentos da pesquisa para as quatro UFP estudadas (Figura 3).

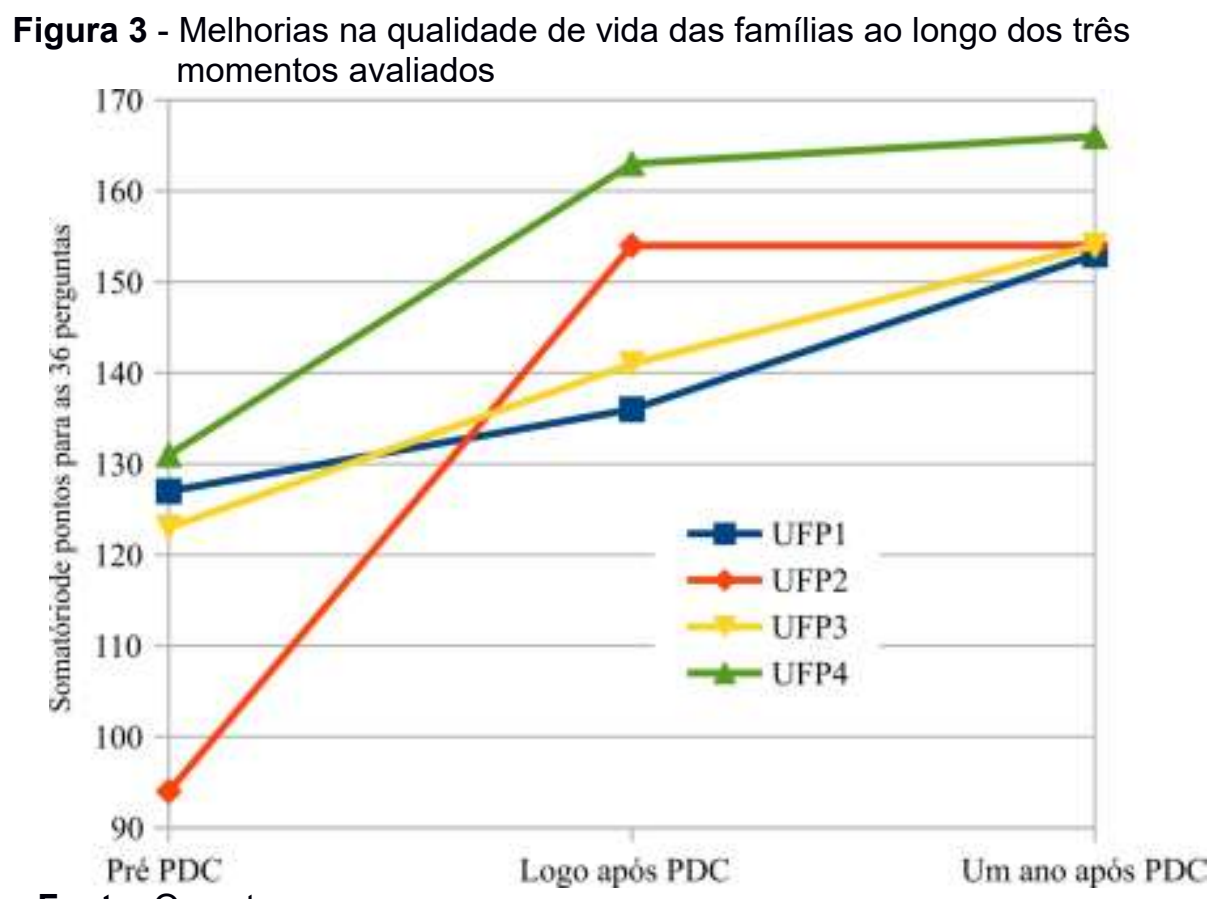

Fonte: Os autores 
O gráfico proporciona uma síntese que permite comparar a evolução da qualidade de vida entre as UFP, considerando que o somatório dos escores para cada ética reflete o grau de incorporação dos princípios de planejamento da permacultura.

De modo geral, percebe-se que houve uma melhoria substancial no momento logo após o PDC para as UFP 2 e 4 e uma melhora mais branda para as UFP 1 e 3 . Essa diferença pode estar atrelada ao fato das UFP 2 e 4 serem manejadas por pessoas que estavam mais predispostas às mudanças e não são totalmente dependentes da geração de renda a partir da produção da propriedade. No que tange as UFP 1 e 3, estas dependem apenas dos rendimentos oriundos da própria produção para se manterem economicamente, fazendo com que haja uma inibição para a troca de manejo, uma vez que a geração de renda pode ser comprometida.

Acredita-se que estes fatores são determinantes nas diferenças de evolução da qualidade de vida da UFP avaliada através do MESMIS permacultural, pois, mudar a gestão da propriedade e arriscar uma nova forma de manejo é sempre uma condição delicada. Essa ação envolve empreendedorismo e capacidade para sair da "zona de conforto" a que se está submetido.

\section{CONCLUSÕES}

A adoção de uma ferramenta personalizada para a avaliação da qualidade de vida em propriedades permaculturais se faz necessária, devido ao seu objetivo principal não ser apenas a geração de divisas financeiras, por intermédio da comercialização da produção, mas sim buscar meios para estabelecer uma conexão com a natureza, alimentar a autossuficiência para depois, caso hajam excedentes, comercializá-los ou trocá-los de forma a fortalecer a comunidade do entorno, fomentando assim a partilha justa, a qualidade de vida dos envolvidos e a manutenção dos ecossistemas, que são provedores da abundância de recursos naturais ofertados.

Conclui-se que a aplicação do MESMIS Permacultural se mostrou adequada aos objetivos propostos pelo projeto Terra permanente, pois conseguiu demonstrar com fidelidade a evolução da qualidade de vida das famílias envolvidas na pesquisa. Cabe destacar, então, que o MESMIS permacultural tem potencial para ser aplicado em outras pesquisas cujo enfoque seja abordar os princípios da permacultura. 


\section{AGRADECIMENTOS}

Os autores agradecem aos permacultores/as participantes e ao fomento financeiro desta pesquisa viabilizado pela Chamada MCTI/MAPA/MDA/MEC/MPA/CNPq No 81/2013.

\section{REFERÊNCIAS}

CERTOMÀ, C.; MIGLIORINI, P. The Evaluation of Sustainability of Organic Farms in Tuscany. In: GÖKÇEKUS, H.; TÜRKER, U.; LAMOREAUX, J. W. (Eds.). Survival and sustainability: environmental concerns in the 21st Century. Berlin, Heidelberg: Springer Berlin Heidelberg, 2011. p. $165-177$.

DIXON, M.; SPOTTEN, S. Future care. Disponível em:

<https://permacultureproductions.com/2014/01/future-care/>. Acesso em: 26 out. 2017.

GIULIANI, G. M. Neo-ruralismo: o novo estilo dos velhos modos. Revista Brasileira de Ciências Sociais, v. 14, p. 59-67, 1990.

HARLAND, M. Future care: redefining the third permaculture ethic. Disponível em: <https://www.permaculture.co.uk/>. Acesso em: 14 mar. 2018.

HOLMGREN, D. Permacultura: princípios e caminhos além da sustentabilidade. Tradução Luzia Araújo Porto Alegre: Via Sapiens, 2013.

LIKERT, R. A technique for the measurement of attitudes. New York: The Science Press, 1932.

LOCKYER, J.; VETETO, J.R. Environmental anthropology engaging ecotopia. New York, London: Berghahn Books, 2013.

LÓPEZ-RIDAURA, S.; MASERA, O.; ASTIER, M. Evaluating the sustainability of complex socioenvironmental systems. the MESMIS framework. Ecological Indicators, Hyatt, v. 2, n. 1, p. 135148, 1 nov. 2002.

MOLLISON, B. Introdução à Permacultura. Tradução de André Soares. Brasília: MA/SDR/PNFC, 1998.

MOLLISON, B. Permaculture: a designers' manual. 8. ed. Tyalgum, Austrália: Tagari Publication, 1999.

MOLLISON, B. C.; HOLMGREN, D. Permaculture one: a perennial agriculture for human settlements. Tyalgum, N.S.W.: Tagari, 1987.

NETWORK OF WELLBEING. Exploring the links between wellbeing and permaculture. Disponivel em: <http://www.networkofwellbeing.org/index.php/blog/post/exploring-the-linksbetween-wellbeing-and-permaculture>. Acesso em: 02 set. 2018.

ROSS MARS; JENNY MARS. Getting started in permaculture. 2. ed. [s.I.] Chelsea Green Publishing, 2007. 
SANTOS, L. A permacultura como dispositivo de ressignificação do espaço geográfico. Florianópolis, SC: Trabalho de Conclusão de Curso de Graduação em Geografia. Universidade Federal de Santa Catarina, Centro de Filosofia e Ciências Humanas, 2014. Disponível em: <https://repositorio.ufsc.br/xmlui/handle/123456789/182866>. Acesso em: 02 set. 2018.

TEN BRINK, B. J. E.; HOSPER, S. H.; COLIJN, F. A quantitative method for description \& assessment of ecosystems: The AMOEBA-approach. Marine Pollution Bulletin, Environmental Management and Appropriate Use of Enclosed Coastal Seas. v. 23, n. Supplement C, p. 265270, 1 jan. 1991.

VERDEJO, M. E. Diagnóstico rural participativo: guia prático - DRP. Brasília: MDA /Secretaria da Agricultura Familiar, 2010.

WITHONEPLANET. The tropical permaculture guidebook: a gift from timor-leste international Edition 2017. Timor Leste: 2017. Acesso em 10 de jul 2018. Disponível em:

<http://withoneplanet.org.au/permaculture-guidebook/> 